\title{
Establishment of Higher Education Institutions and New
}

\section{Firm Entry}

\section{Rui Baptista}

Department of Engineering and Management and IN+ Centre for Innovation, Technology, and Policy Research, Instituto Superior Técnico, Technical University of Lisbon And Max Planck Institute of Economics, Jena, Germany

Av. Rovisco Pais, 1049-001 Lisbon, Portugal.

Ph: +351.218.417.379; Fax: +351.218.496.156.

E-mail: rui.baptista@ist.utl.pt

\section{Francisco Lima}

Department of Engineering and Management and Centre for Management Studies (CEG-IST), Instituto Superior Técnico, Technical University of Lisbon

Av. Rovisco Pais, 1049-001 Lisbon, Portugal.

Ph: +351.218.417.379; Fax: +351.218.496.156.

E-mail: francisco.lima@ist.utl.pt

\section{Joana Mendonça (corresponding author)}

IN+ Centre for Innovation, Technology and Policy Research,

Instituto Superior Técnico,

Av. Rovisco Pais, 1049-001 Lisbon, Portugal.

Ph: +351.218.417.379; Fax: +351.218.496.156.

E-mail: joana.mendonca@ ist.utl.pt. 


\begin{abstract}
The presence of universities has generally been associated with technological entrepreneurship. But what is the real impact of new universities on the levels of firm creation in a region? The present paper uses policy evaluation methodologies and longitudinal data on the establishment of higher education institutions in Portuguese municipalities for the period 1992-2002 to examine its effect on entry rates of new firms in different sectors. We find that the establishment of a new university has a positive and significant effect on subsequent levels of knowledge based firm entry in municipalities, and a negative effect on the levels of entry in other sectors, such as lowtech manufacturing.
\end{abstract}

Keywords: Universities; Entry Rates; Regional Development; Policy evaluation; Propensity Scores. 


\section{Introduction}

A variety of studies have examined the role played by universities in promoting entrepreneurship. Some of these studies have been carried out at the micro level, examining institutional strategies and performance in technology transfer and commercialization (see, for instance, Di Gregorio and Shane, 2003; Grandi and Grimaldi, 2005; Markman et al., 2005; and Clarysse et al., 2005). Other studies have been carried out at a more macro level, examining the impact of universities on entrepreneurial activity, focusing particularly in nearby regions. Audretsch et al. (2005) found that, in general, new knowledge based firms have a high propensity to locate close to universities. Lindelof and Lofsten (2004) claim that co-operative resources provide new technology based firms located in university science parks with competitive advantages over other new technology based firms. Academic research and development expenditures have been found to be significantly associated with rates of new firm formation across regions (Lee et al., 2004). There is strong evidence for the United States of a growth effect of clusters influenced by active research universities (Feldman, 2000).

In modern economies, universities generate a steady flow of novel technical ideas, with the system of public research and higher education institutions largely responsible for the creation of technological capacity (Mazzoneli and Nelson, 2007). In addition to their traditional role as sources of ideas, knowledge and intellectual capital, universities are agents of innovation through the development and commercialization of ideas generated by academic R\&D. Entrepreneurial universities enhance regional development and international competitiveness and their role is especially important in 
structurally weak and peripheral regions where universities tend to have a monopoly over the production of intellectual capital.

The presence of universities generates positive externalities both through performing knowledge-generating R\&D activities and educating specialized human capital capable of absorbing such knowledge. Firms can cultivate relationships with universities, participating in research consortia and partnering with academics that do related scientific work (Audretsch and Feldman, 2004). For instance, personal networks of academics and industrial researchers facilitate the commercial exploitation of knowledge generated at universities by existing firms or university spin-off start-ups. Moreover, fresh graduates may be important channels for disseminating the latest knowledge from academia to the local industry (Varga, 2000). Empirical studies have found that new firms are highly likely to be started in the home region of their founders (Klepper, 2002). As a result, universities and other research institutions can become important focal points for regional economic development.

The presence of a university in a region is an additional factor influencing the location decision made by new firms. This influence should be greater in industries where new knowledge plays an important role. The transmission of new and uncodified knowledge tends to occur only within limited geographic areas, embedding resulting economic activity within the region (Baptista and Swann, 1999). As a result, it is expected that access to local knowledge sources is particularly significant for high technology and knowledge based manufacturing and services.

Until 1974, the Portuguese higher education system was reserved for elites, and characterized by a low number of students. After the April 1974 revolution, education was democratized and the higher education system was expanded, integrating a growing 
number of students. In the 1980 s the growth of the private higher education sector garnered political support (Correia et al., 2002). Due to this political context, several new private and public universities emerged.

While the establishment of new higher education institutions in Portugal was probably not deliberately aimed at stimulating new firm creation, the theoretical and empirical work linking universities to knowledge spillovers and entrepreneurial activity suggests that it is likely that such stimulus has occurred. The present paper examines whether the policy of establishing new higher education institutions had positive effects on subsequent regional levels of new firm entry. For this, policy evaluation techniques are used. More specifically, first differences and propensity score matching methods are applied in order to identify shifts in firm entry rates in regions where new universities were established versus regions with similar characteristics that maintained the same number of universities.

Our results indicate that the establishment of new higher education institution in a region has a positive impact on the lagged share of new firm entry in knowledge intensive sectors, which is followed by a significant decrease in the entry of firms in low-technology sectors. In general, our results suggest that universities contribute to the regional development of knowledge related businesses.

The paper is organized as follows. The next section presents some background on the role played by universities in regional development, presenting the research questions addressed. Section 3 presents the data and methodological approach used in the present study, while section 4 reports and discusses the results obtained. Section 5 presents our main conclusions, and highlights avenues for improving and broadening this research. 


\section{Universities and new firm creation}

\subsection{Universities and firm location}

One of the major socio-economic trends observed since the 1970s is the rise of entrepreneurship as a driver of innovation, competitiveness and economic development. Both academics and policy makers claim that entrepreneurial activity is vital to economic progress. As a result, government policies fostering new firm creation have been adopted by many countries. Empirical research suggests that the kinds of entrepreneurial efforts more likely to impact on subsequent economic development and employment growth are knowledge based firms (Baptista and Preto, 2009). Knowledge based entrepreneurial activity requires a steady flow of novel ideas in order to flourish. The existence of human capital with the technological knowledge required to recognize and implement entrepreneurial opportunities arising from novel ideas is essential for successful technology commercialization. Universities and R\&D laboratories are fundamental sources of technical knowledge which can be commercialized. Universities and polytechnic institutes also play a major role in educating human capital capable of recognizing and implementing technological opportunities.

Recent research addresses the issue of technology transfer and commercialization, that is, the mechanisms and incentives through which universities bring knowledge from the laboratory to the market. Fewer works address the regional dimension of university knowledge transfer. As a variety of research streams have demonstrated the importance of geographical proximity for the transmission of new knowledge, it is reasonable to expect that the economic exploitation of new knowledge will occur close to the sources generating it. 
Complex technological knowledge (seemingly the most valuable type of knowledge) usually contains a strong element of tacitness, meaning its flow and diffusion is constrained by the geographic proximity and extent of interaction between individuals within whom the tacit component resides. Considering tacit knowledge as an important element for new innovative firms, access to this type of knowledge can become a major determinant in the competitiveness of regions and location of these firms (Audretsch et al., 2004). A host of empirical studies have confirmed that knowledge spillovers are geographically bounded (Jaffe, 1989, Anselin et al., 1997). Accordingly, the location decision of new firms appears significantly influenced by access to knowledge spillovers, including specialized human capital and institutions performing R\&D activities (Audretsch et al., 2005). In addition, the propensity to cluster geographically should be greater in industries where new knowledge plays a more important role because such knowledge is less likely to be codified and simple to transmit over great distances (Baptista and Swann, 1999).

Recent literature advocates that knowledge spillovers play an important role in fostering entrepreneurship and innovative activity (Sorenson and Audia, 2000; Baum and Sorenson, 2003). Companies in innovative sectors tend to choose locations where significant knowledge-generating activities associated with these sectors occur (Audretsch and Stephan, 1996; Zucker et al., 1998, 2002). These activities may be performed by universities or other firms and implies the presence of world class scientific research and human capital. Spillovers from universities, as well as from private firms, have been recognized as key sources promoting firm innovation and performance (Stuart and Sorenson, 2003). Stahlecker and Koschatzky (2004) indicate that spatial proximity matters for the founding and early performance of firms in the 
knowledge intensive business services sectors. Also, Capello (2002) finds that high technology industries display high spatial concentration. In contrast to start-ups with traditional products and processes, knowledge based firms tend to offer new or improved products, operating in markets in early development stages. Thus, access to knowledge sources should be particularly significant for high technology and knowledge based industries and services.

\subsection{Universities as knowledge sources}

Modern universities have a role in the dissemination and transmission of knowledge (Caraça et al., 2000). In particular, university research contributes to the basic stock of scientific knowledge available in any country or region and it appears to have potential to improve national competitiveness (Spencer, 2001). Research identifies the important role that universities play in generating knowledge spillovers (Audretsch et al., 2004). Studies find that academic research is linked to a high percentage of product innovations, and that the development of certain sectors happens in countries where there are strong university research programs in related areas. Public research is used not only to generate ideas, but also to help completing existing R\&D projects in firms.

Start-ups in particular can be a vehicle to transfer university research into commercial innovation, especially in science-based sectors (Laursen and Salter, 2004). Geographical proximity of an academic institution to a knowledge intensive industry may be a source of positive knowledge externalities, since firms can cultivate relationships with universities, establishing partnerships with academics doing related scientific work, thus allowing the sharing and exchange of tacit knowledge (Audretsch and Feldman, 2004). Cooperative relationships are a channel for knowledge spillovers, and cooperation is favoured by geographical proximity (Fritsch, 2001). For instance, 
personal networks of academics and industrial researchers, may lead to the commercial exploitation of knowledge generated at universities by existing firms or university spinoffs. The possibility to elaborate research partnerships with academic institutions may also affect positively the absorptive capacity of firms (Scott, 2003).

Fresh graduates may be important channels for disseminating the latest knowledge from academia to the local high tech industry (Varga, 2000). Also students can provide a channel to transmit knowledge from the university to the firm, where it can be commercialized (Audretsch et al., 2004). In addition, the establishment of new firms can also be advantageous to the universities, since they can make the institutions more attractive to students, faculty and other partners. By creating new knowledge and training people, universities support the formation of new firms, and therefore are an important source of investment ideas for venture capitalists (Lerner, 2005).

Given that the commercialization of knowledge depends on knowledge generation by universities and public R\&D institutions, as well as on R\&D activities by firms, a low level of new business formation in knowledge dependent sectors could be associated with a lack of knowledge-generating sources (Cohen and Levinthal, 1989). Acs et al. (1994) find that small firms receive R\&D spillovers generated by both universities and the $\mathrm{R} \& \mathrm{D}$ centres of their larger counterparts, and that these spillovers are apparently more significant in stimulating innovative activity by small firms than by larger ones. Evidence of local spatial externalities between university research and high technology innovative activity is also found by Anselin et al. (1997). Feldman (2000) reports strong evidence favouring a growth effect of geographical clusters influenced by active research universities in the United States, while Fisher and Varga (2003) provide evidence of the importance of geographically mediated knowledge spillovers from 
university research activities to regional knowledge production in the Austrian high tech industry. Bania et al. (1993) find that the relationship between university research and firm births varies across industrial sectors. Also, the role played by universities in the commercialization of knowledge has increased over time; Henderson et al. (1998) have found evidence of an increase in the rate of technology transfer to the private sector.

\subsection{The Emergence of New Higher Education Institutions in Portugal}

On April 25th, 1974 there was a revolution in Portugal, ending the authoritarian regime that lasted almost for half a century. During the regime there was extensive state regulation and predominantly private ownership of the means of production. The state exercised widespread authority regarding private investment decisions and the level of wages. Following the revolution, the Portuguese higher education system grew significantly, as a consequence of a political effort to democratize and facilitate access to universities, and an associated increase in the demand for higher education. Since then, several public and private higher education institutions have been established across the country, giving rise to a private higher education sector and to a network of polytechnic institutions supported by the government. At the same time, important educational reforms took place in the other levels of education. There was an increase in compulsory schooling (from six years, for individuals who entered the school system in 1969, to nine years, for those who entered in 1986), followed by the reform of the secondary school curricula, and the extension of the university system (Kiker and Santos, 1991). These reforms had consequences in the number of enrolled students, which increased from an average of 30,000 in the 1960 s to 400,000 in the 1990 s (Horta, 2007; Correia et al., 2002). This increase is also visible in the substantial evolution in the number of researchers, from 11599 full time equivalent (FTE) in 1995 to 21003 
FTE in 2005; the number of people working in R\&D went from 15465 FTE in 1995 to 25651 FTE in 2005 (OECD, 2007).

The Portuguese educational system has experienced significant improvement and expansion over the last 35 years. The emergence of several new higher education institutions represented an attempt to offer new degrees and address specific local or regional needs. In particular, new private higher education institutions tried to explore market niches that remained untouched (Correia et al., 2002). This policy development enables us to recognize the creation of new higher education institutions in specific regions and address their effects.

\subsection{Hypotheses Formulation}

Since not all regions gained new universities, by doing cross-regional analysis we are able to identify the economic impact of new higher education institutions. If universities foster entrepreneurial activity, we can assume that the establishment of a university will impact the number of start-ups in its region. In this mindset, we wish to address the following research question: What is the impact of the establishment of a new university on the levels of firm entry in a region? We address this research question by testing the following hypothesis:

H1: The establishment of a new higher education institution in a municipality has a positive effect on subsequent levels of new firm entry in that municipality.

Furthermore, it is not clear if universities will affect entrepreneurial activity across industries, or if this effect will be more pronounced in knowledge related sectors. Firms in high-technology industries often seek to increase levels of intellectual capital through the use of external sources, making proximity to a university more important. Thus, we test a second hypothesis: 
H2: The impact of a new higher education institution in a municipality will vary according to the sector considered.

In particular, we assume that there should be a more short term impact on the entry of new firms, focused on supplying the new higher education institutions with services and technology. We also expect that there will be a gradual effect, over the long term, which will take some years to peak, whereby new firms are started by faculty and graduates of these institutions as a consequence of knowledge spillovers generated by the educational and research activities. In addition, we assume that activities in knowledge based industries and services will benefit more from locating in the proximities of higher education institution and we expect these new institutions to have a bigger impact in knowledge dependent sectors.

\section{Regional Data on New firms and Higher Education Institutions}

Data on firm dynamics and levels of human capital are drawn from the Portuguese Quadros de Pessoal database. This is a longitudinal matched employer-employee database built from mandatory information submitted by firms to the Portuguese Ministry for Employment and Social Security. It includes extensive information on all private firms, establishments, workers and business owners in the Portuguese economy. There are on average over 145,000 firms, 170,000 establishments and 2 million workers in each annual return, which are fully linked through the use of unique identification numbers, thus allowing the recognition of both entering and exiting firms, as well as the opening and closure of subsidiary establishments. For each firm, data are available for size, age, location, sector and number of establishments. Data on business owners and employees for each firm and establishment include gender, age, function, tenure, 
schooling and skill levels. ${ }^{1}$ The present study distinguishes firms in manufacturing sectors and in knowledge intensive business services, from the remaining sectors, making use of OECD classifications (OECD, 2002). Appendix 1 presents a sector description. We identified entry by observing the appearance of a new firm identifier in the database and comparing this entry with the earliest employee admission date. We considered entry if the workers' admission date did not differ for more than two years from the firms' entry date identified. Firms for which the entry year was not identified were not included in the analysis. A dataset was built containing all new firms starting their activity in the period 1992-2002 in the sectors considered. Data were aggregated at the municipality level, including all 275 continental Portuguese municipalities. ${ }^{2}$

Data for higher education institutions were obtained from the Portuguese Ministry for Science, Technology and Higher Education. The dataset includes information for all Portuguese higher education institutions, both public and private, between 1992 and 2002. For each year, institutions provide information on the number of students, number of graduates and the degrees provided. This information is collected and aggregated at the municipality level.

Table 1 presents the descriptive statistics for the variables used. Portuguese municipalities display significant differences in terms of number of start-ups (Baptista and Mendonça, 2009). There is also significant demographic dispersion, with municipalities along the coast having growing population densities, while those inland experiencing population decline. This regional asymmetry is reflected in the demography of new firms; indeed, previous research indicates that Portuguese

\footnotetext{
${ }^{1}$ See Cabral and Mata (2003) for a description of the quality and coverage of the data.

${ }^{2}$ Municipalities located in the Islands of Madeira and Azores are excluded due to the lack of available data.
} 
entrepreneurs tend to start firms in the region where they live, and do not often choose to locate their business elsewhere (Figueiredo et al., 2002).

Insert Table 1 about here

The differences between municipalities are controlled for using a series of variables which are known to influence the location of new firms. We use population density, which can be regarded as measure of regional demand size. Thus, regions with higher population density are more likely to attract more start-ups (Kangasharju, 2000). We control for the share of micro firms, which represents the business environment (intensity of competition and barriers to entry) of the region. Regions with a higher percentage of small firms tend to attract more new (small) firms. The regional workforce is used as a measure of human capital availability in the region; regions with more workers will attract more new ventures. In the estimations we used the logarithm of this variable to narrow the distribution, limiting the effects of outliers. The distances to the main urban centres of Oporto and Lisbon, are used to capture access to the country's largest markets, and access to information about market and regulatory requirements (Figueiredo et al., 2002). More new firms tend to locate closer to the larger urban centres. Finally, we introduce in our estimation year dummies to capture time/business cycle effects.

In the present paper, we evaluate the effects of the establishment of new higher education institutions by measuring its impact on the formation of new firms. Thus, we compare levels of firm entry in municipalities where new higher education institutions were established with firm entry in municipalities where no new institutions were 
established. We check whether or not the establishment of a new institution significantly affects subsequent rates of new business formation, and how this effect varies across sectors. As such, we consider the establishment of a new institution to be a treatment variable and evaluate the impact of this treatment by creating a dummy variable equal to one where new institutions are established, versus zero for those municipalities where no new higher education institutions were established. We compare the group of municipalities where a new higher education institution was established with two control groups: A) municipalities where the number of institutions is zero and remains zero during the entire time of the study; B) municipalities where the number of institutions is different from zero and remains constant. ${ }^{3}$ We excluded municipalities where there was a decrease in the number of institutions, because there may be effects of this decrease that we are unable to control for. We also excluded municipalities where new institutions were established outside the time span of our analysis, since these new institutions have impacts that we cannot identify and we wished to ensure we were observing only the effect of new institutions.

Between 1992 and 2002, 46 municipalities had a new institution established while multiple institutions were established in 14 other municipalities. There are 204 municipalities with no institutions in the same period (group A), and 17 municipalities for which the number of institutions was one or more, and remained constant throughout the time period (group B).

In this analysis, we choose to observe the treatment on the years 1993 and 1994, so that we have at least two years before treatment to control for pre-treatment characteristics. Since we compare municipalities in the different groups, we need to be

\footnotetext{
${ }^{3}$ There are no municipalities where an institution of higher education closed and was replaced by another.
} 
able to observe the municipalities at least two years before the treatment, to make sure we compare municipalities with similar characteristics regardless of new institution establishment. In addition, we want to have a large number of years after treatment in order to distinguish between the short term effects and the long term effects. Furthermore, using two adjacent years avoids comparison of treatment in different environmental conditions.

In 1993 and 1994 we identified 17 new higher education institutions in 17 different municipalities. Of these institutions, six are private schools, while eight of the eleven state schools are polytechnics. Five of the 17 new institutions have active research centres and develop research activities, and four provide technology related degrees. There are 204 municipalities without any higher education institutions throughout the period of analysis (control group A), and 17 that already had at least one higher education institution without any additional institutions established in the period of analysis (control group B). The time scale is used with reference to the treatment period: for municipalities where a new higher education institution was established, the time zero $(t=0)$ corresponds to the year of establishment (i.e. of treatment, 1993 or 1994); for municipalities where no higher education institutions were established, the time $t=0$ is set to the first year of treatment (1993).

Table 2 displays the relevant characteristics two years before treatment $(t=-2)$ across the groups of municipalities considered. The control group A, which has no universities or polytechnics throughout the whole period of analysis, displays lower average levels of education, population density, and number of workers, as well as smaller firms on average. In addition, group A is dominated by municipalities relatively distant from the two main urban centres of Lisbon and Oporto. In contrast, 
municipalities in the treated group display higher average levels of education, higher population density, and greater numbers of employed workers. In our analysis we control for these pre-treatment differences by matching municipalities within each group that have similar pre-treatment conditions. Without such matching, it is impossible to compare the two groups as shown by the figures presented in Table 2 . The same pattern of differences in the pre-treatment variables is observed for group B (municipalities with number of institutions constant and different from zero). The municipalities in this group are larger than those in group A, but smaller than those treated, as measured by population density and number of workers. The same type of relationship is found for average workforce years of education. As expected, these municipalities are closer to the two main urban centres. Moreover, the share of small firms is smaller than in municipalities belonging to group A and the treated group.

Insert Table 2 about here

\section{Applying the Propensity Score Mathing Method}

We wish to determine the effect of the establishment of new universities on the regional subsequent levels of new firms. The establishment of new universities can be seen as an exogenous shock, and provides the setting of a natural experiment. A natural experiment always has a control group, which does not experience any change, and a treatment group which is affected. In this case, the exogenous event is the establishment of higher education institutions during the 1990s because of government policies designed to change the structure of the higher education sector while increasing the 
level of education in Portugal. Accordingly, the control group consists of those municipalities without any changes in the number of higher education institutions they host (in the entire period from 1992 to 2002), while the treatment group consists of those municipalities where a new higher education institution was established in either 1993 or 1994.

We start by applying a first-differences method to determine the effect of the establishment of a new higher education institution on entry rates. A first differencedequation of the entry rates of firms is estimated using OLS, distinguishing the control group from the treated group. The treatment is introduced using a dummy variable which assumes the value 1 (one) for treated regions, and 0 (zero) otherwise. The treatment effect is captured in the municipality entry rates. We differentiate the entry rates across adjacent time periods for the same cross-sectional units (municipalities). We control for differences between municipalities by including in the estimation our set of control variables, which are likely to affect the rate of new firms in regions: population density; the share of micro firms; regional workforce $(\log )$; the distances to the main urban centres of Oporto and Lisbon; and year dummies to capture time/business cycle effects, which are also differenced over time.

It is likely that the impact of new universities is not limited to the one region and will affect surrounding regions. Nevertheless, results obtained by Figueiredo et al. (2002) show that founders of new firms in Portugal tend to locate their businesses in close proximity to their homes, and therefore a significant number of entrepreneurs set up their businesses in their own municipality. Also, Baptista and Mendonca (2009) do not observe spatial auto-correlation in new firm entry in Portuguese regions. Therefore, we focus our analysis on the effect in each municipality, not accounting for spatial 
correlation. The matching of regions guarantees that each region is only compared with other regions with similar characteristics.

With the first-differences method we are unable to capture the effect of a new university on the one year lag of regional rates of entry of firms given that the estimator on the treatment variable is not statistically significant. ${ }^{4}$ The first-differences estimator compares the group of treated regions with the group of non-treated regions, regardless of individual characteristics within the two groups. Since we have very heterogeneous groups of municipalities, which cannot be directly compared, we are unable to isolate the effect of the establishment of a new higher education institution. Another reason for these results is that one year differences are not enough to observe any effects of the new institutions in the regional levels of new firm formation. It is reasonable to assume that a new university will take more than one year to affect new firm creation in a region. This may be even more important for knowledge intensive activities that are generated through knowledge spillovers resulting from university $R \& D$, or by companies started from graduates coming out from these institutions.

In order to observe the treatment effect more accurately, we use a different matching technique, allowing for more accurate comparisons between municipalities. The propensity score matching estimator allows us to match municipalities according to their characteristics and observe the effect more than one year after the establishment of new institutions. The propensity score matching method is a matching technique which makes the distribution of observable characteristics of treatment and control groups similar (Rosenbaum and Ruben, 1983). The difference is that we now compare treated municipalities with non-treated municipalities that are similar in a number of

\footnotetext{
${ }^{4}$ Results are available from the authors upon request.
} 
characteristics, controlling for the heterogeneity of the treated group. The principal advantage of propensity scores matching methods is this correction for sample selection bias due to observable differences between the treatment and comparison groups (Dehejia and Wahba, 2002).

The propensity score is the conditional probability of receiving a particular treatment (in this case, having a new higher education institution) given a vector of observed covariates (pre-treatment characteristics):

$$
p(X) \equiv \operatorname{Pr}\{D=1 \mid X\}=E\{D \mid X\}
$$

Where $\mathrm{D}=\{0,1\}$ is the indicator of exposure to treatment and $\mathrm{X}$ is the multidimensional vector of pre-treatment characteristics (Becker and Ichino, 2002).

We estimate the propensity score of the treatment on the control variables using a probit model and stratify individuals in blocks according to the estimated score. We estimate the probability of having an increase in the number of universities, given the municipalities' characteristics from period $t=-2$ (pre-treatment variables). The propensity score is estimated and the balancing property is tested. The balancing property ensures that the means of each characteristic do not differ significantly between treated and control municipalities, which allows us to compare municipalities of the different groups that are similar in terms of their pre-treatment characteristics. This estimated probability of another institution conditional on the full set of covariates included in the regression is used to match treated and control municipalities. The matching involves pairing treatment and comparison units that are similar in terms of their observable characteristics (Dehejia and Wahba, 2002).

Naturally, other factors besides the presence of universities influence the levels of new firm formation in regions, so we need to control for these factors. Thus, the 
matching between municipalities is done by using variables that affect the probability that new firms will locate in each municipality, regardless of the existence of higher education institutions (Figueiredo et al., 2002; Baptista and Mendonca, 2009). These factors include the size of the workforce in the region (log), the share of micro firms in the region (as a measure of the level of competition and barriers to entry), and the distances to the markets of the two largest urban areas (Lisbon and Oporto). The results for this estimation are presented in Table 3.

Insert Table 3 about here

Afterwards, we use the stratification method to match the treated group and the control groups' observations and to estimate the Average effect of Treatment on the Treated (ATT). With stratification matching, the range of variation for the propensity score is divided in intervals such that within each interval treated and control units have on average the same propensity score (Becker and Ichino, 2002). The ATT is then estimated within each block:

$$
\tau_{q}^{s}=\frac{\sum_{i \in I(q)} Y_{i}^{T}}{N_{q}^{T}}-\frac{\sum_{j \in I(q)} Y_{j}^{C}}{N_{q}^{C}}
$$

Where I(q) is the set of units in block q while $N_{q}{ }^{T}$ and $\mathrm{N}_{\mathrm{q}}{ }^{\mathrm{C}}$ are the numbers of treated and control units in block q, and Y represents the outcome variable. The estimator of the ATT based on this method is then computed as:

$$
\tau^{s}=\sum_{q=1}^{Q} \tau_{q}^{s} \frac{\sum_{i \in I(q)} D_{i}}{\sum_{\forall_{i}} D i}
$$


Where the weight for each block is given by the corresponding fraction of treated units, and $\mathrm{Q}$ is the total number of blocks. The matching estimator computes the average difference in the outcome of interest (share of new firms) between the treatment and control group.

We observe the effect of the treatment in the variation on the share of new firms in the region from the pre-treatment $(t=-2)$ to the post-treatment $(t=3, t=5$ and $t=7)$. The main argument for these time differences is that we need at least three years to observe any effect of a new institution establishment on new firm formation, since it takes at least three years for graduating students to leave with a bachelor's degree, and a similar period should be considered for the generation of significant results from $R \& D$ that might spill over to the region.

We compare municipalities where there was a new institution with two control groups: A) municipalities where the number of institutions is zero and remains zero during the entire time of the study; B) municipalities where the number of institutions is different from zero and remains constant. We then distinguish effects for two sectors: knowledge based firms and low technology manufacturing. In addition, we try to separate the effect on high technology manufacturing, ICT and knowledge intensive services. The results are presented in Tables 4 to 7 .

In Table 4 we use the difference in share of new firms in the sample as the outcome variable. We observe positive coefficients five years after treatment when compared with control group B. This means that, for the general manufacturing firms, the establishment of a new university in a region generated an increase of $6.5 \%$ in the share of new firms 5 years after the entrance of a new higher education institution. However, this result is only significant at the $10 \%$ level. All other estimations provided 
insignificant results. Such results mean that there is no significant difference in the rates of new firm entry between treated municipalities and the control groups, when considering the manufacturing sectors.

Insert Table 4 about here

In Table 5 we present results for knowledge based firms. We observe that the establishment of new universities has a positive impact on the entry of firms in knowledge related activities. This positive effect is observed in the differences of the shares of new firms three and five years after treatment. When we use both control groups together, we obtain an effect of $21 \%$ and $24 \%$. When compared only to group A the effect increases to $30 \%$ and $33 \%$. Comparing with control group B provides no significant results. For the difference in the shares of new knowledge based firms seven years after treatment, we observe an increase of $27 \%$ when using both control groups, but this impact is not visible when comparing control groups A and B separately. Access to external knowledge sources is important for firms' innovative activity. Thus we would expect sectors that are more dependent on new knowledge will benefit more from locating near a university. According to Audretsch et al. (2005), younger firms are more likely to locate closer to universities with a large number of students. These results reflect this tendency and provide evidence of the role played by higher education institutions in the shift toward knowledge based sectors, visible in municipalities where a new university was established. The results are strengthened when we compare the treated group with municipalities that have no higher education institutions. 
The type of data under scrutiny do not allow for any indication of the interaction universities actually have with the surrounding firms, and between university spin-offs and new firms attracted to the region. While previous literature suggests that if firms have easier access to more knowledge, they will tend to use more knowledge and incorporate it in their commercial activities, we do not observe the actual flows. Still, Costa and Teixeira (2005) conclude that the presence of a university is critical to innovative activities of new firms, having an impact on regional knowledge network flows and density. This linkage between universities and industrial innovation is tighter in knowledge intensive sectors than in other less knowledge intensive activities (Laursen and Salter, 2004).

Insert Table 5 about here

The opposite effect is observed when we focus on low tech firms, as seen in Table 6. All estimations revealed a negative and significant coefficient, showing a negative impact of new higher education institutions on entry of firms in these sectors. There is evidence that low-technology sectors benefit less from locating close to a university, since they are less likely to use it as a source of knowledge and as a cooperation partner (Faria et al., 2007). These results are consistent with a shift toward the "new economy". The decline in entry in low-technology sectors is stronger in regions where a new university is established. Again, these results suggest that higher education institutions play a role in shaping the economic activity of regions.

Insert Table 6 about here 
We attempt to examine whether entry in knowledge based firms is more focused on high technology activities, ICT, or knowledge intensive services, by dividing our sample into these three sectors. The results are presented in Table 7. In the knowledge intensive services sample, we obtain a positive effect in the difference of the share of new firms between $t=-2$ and $t=5$, when comparing the treated group with control group B. Thus, we observe a 9\% increase in firm entry for knowledge intensive services in the treated group five years after treatment, versus regions with a constant number of universities. This may be a combination of short and long term effects. On the one hand, service firms may be established in the short term to serve the needs of new institutions in the municipality; on the other hand, some firms are established in the long term by faculty members and students from the new institutions. All other estimations have insignificant results. Such results are unexpected; we anticipated a positive effect on entry of ICT firms, at least in the short term, taking advantage of the opportunity to serve the new institution. As we increase the time lag, the number of observations in the sample decreases, which does not allow for the identification of any effects.

These results could be consequence of measuring all types of institutions together, without differentiating whether they are technical universities or more focused on humanities and social sciences. There are not enough cases in the context of our empirical setup to make that distinction and to arrive to meaningful results. Firms may benefit from locating close to universities whether it is for privileged access to knowledge or for the availability of qualified human capital. Previous results for Portugal have shown that firms are attracted to locate closer to universities, independently of the type of disciplines they teach (Baptista and Mendonca, 2009). 
Insert Table 7 about here

The results give partial support to hypothesis $\mathrm{H} 1$, which predicted that the establishment of a new higher education institution in a municipality has a positive effect on subsequent levels of new firm entry in that municipality. This impact is only observed in certain sectors, not allowing for the total support of hypothesis H1. In addition, and given that we obtained different results when differentiating between sectors, our results provide support to hypothesis $\mathrm{H} 2$, which stated that the impact of a new higher education institution in a municipality will vary according to the sector considered.

\section{Concluding Remarks}

In this paper we determine the impact of the establishment of new higher education institutions in municipalities on subsequent levels of new firm entry. We study this effect making use of the first-differences and propensity score matching methodologies. This approach captures the effect of an increase in the number of universities within a municipality on the levels of new firm entry in that municipality while explaining the differences between treatment and control groups, and controlling for other factors which affect new firm creation in regions. We compare municipalities where there was an increase in the number of universities with municipalities where there are no universities throughout the entire time period, and with municipalities with a positive, constant number of universities. We find that these three groups (the treatment and the two control groups) have different patterns of new firm entry. 
Testing our empirical hypotheses, we observe that the establishment of a new higher education institution in a municipality has a positive effect on subsequent levels of new firm entry in that municipality (hypothesis H1), but only in certain sectors, and that the impact of a new higher education institution in a municipality will vary according to the sector considered (hypotheses H2). Accordingly, estimations of the average treatment effect reveal a positive impact of the establishment of new universities on the lagged share of new firm entry in knowledge intensive sectors. There is a significant decrease in the entry of firms in low technology industries in regions where a new higher education institution was established. We also observe an increase in the entry of firms in knowledge intensive services five years after treatment. We cannot observe any other effects when dividing knowledge based activities into high-tech manufacturing; ICT and knowledge related services, probably due to the small number of entries observed in these sectors when municipalities are used as the regional unit of analysis. The overall results indicate that the establishment of a new higher education school in a region will contribute to a shift toward the knowledge based economy.

Our analysis contributes to the literature on the role played by universities and regional knowledge bases as sources of entrepreneurial opportunities through the use of data allowing for the application of econometric techniques for the analysis of policy and treatment effects. The identification of the structural determinants that have impact on the growth of start-up rates at a regional level is useful for formulating public policies with an objective of influencing the start-up activity in regions. Many governments have created initiatives to foster technology commercialization, and with that purpose in mind have supported the interaction between universities and regions (Laursen and Salter, 2004). Governments of most OECD countries support interactions 
between universities and industry since these relationships can increase the rate of innovation in the economy, stimulate the development of regional clusters, and consequently increase economic returns from public research investment and regional economic development (Spencer, 2001). As a consequence of these policies, one expects that linkages between firms and universities are established and that they can result in the creation of spin-off firms based on technologies developed by universities (OECD, 2002). However, even without establishing formal relationships, firms and regions can benefit from the presence of a university.

Our results suggest that universities enhance regional development and suggest that less favoured regions would benefit from the establishment of a new higher education institution. Regions can benefit from the presence of universities because their existence allows firms close access to a source of knowledge. In addition, regions with universities are better able to attract more educated people that will also contribute to the level of knowledge and skill available in the region. Our results indicate that the presence of universities can contribute to regional development through the increase of new firms in knowledge intensive sectors. 


\section{References}

Acs Z., Audretsch, D. B. and Feldman, M. P., 1994. R\&D Spillovers and Recipient Firm Size, Review of Economics and Statistics, 76: 336-340.

Anselin, L., Varga, A. and Acs, Z., 1997. Local Geographic Spillovers between University Research and High Technology Innovations, Journal of Urban Economics, 42: 422-448.

Audretsch, D. B. and Stephan, P. E., 1996. Company-Scientist Locational Links: The case of Biotechnology, American Economic Review, 86: 641-652.

Audretsch, D. B. and Feldman, M. P., 2004. Knowledge spillovers and the geography of innovation, Chapter 61 in Handbook of Regional and Urban Economics, vol. 4, Amsterdam: Elsevier, 2713-39.

Audretsch, D. B., Lehmann, E. and Warning S., 2004. University Spillovers: Does the kind of science matter?, Industry and Innovation, 11 (3): 193-205.

Audretsch, D. B., Lehmann, E. and Warning S., 2005. University Spillovers and New Firm Location, Research Policy, 34, 1113 - 1122

Bania, N., Eberts, R. W. and Fogarty, M. S. 1993. Universities and the Start-up of New Companies: Can we Generalize from Route 128 and Silicon Valley? Review of Economics and Statistics, 75: 761-766.

Baptista, R. and Swann, P. 1999. A Comparison of Clustering Dynamics in the US and UK Computer Industries, Journal of Evolutionary Economics, 9: 373-399.

Baptista, R. and Mendonça, J., 2009. Proximity to Knowledge Sources and the Location of Knowledge Based Start-ups, Annals of Regional Science, DOI: 10.1007/s00168-009-02894.

Baptista, R. and Preto, M.T., 2009. New Firm Formation and Employment Growth: Regional and Business Dynamics, Small Business Economics, DOI: 10.1007/s11187-009-9254-y. 
Baum, J.A.C. and Sorenson, O. 2003. Advances in Strategic Management: Geography and Strategy, Vol. 20. JAI Press, Greenwich, CT

Becker, S.O. and Ichino, A., 2002. Estimation of Average Treatment Effects Based in Propensity Scores, Stata Journal, 2: 358-377.

Cabral, L.M.B., and Mata, J., 2003. "On the Evolution of the Firm Size Distribution: Facts and Theory.” American Economic Review, 93: 1075-90.

Caraça, J., Conceição, P. and Heitor, M.V., 2000. Towards a public policy for the research university in Portugal, Higher Education Policy, 13:181-201.

Capello, R. 2002. Entrepreneurship and spatial externalities: Theory and measurement, Annals of Regional Science, 36: 387-402.

Clarysse, B., Wright, M., Lockett, A., Van de Velde, E., and Vohora, A., 2005. Spinning out new ventures: a typology of incubation strategies from European research institutions, Journal of Business Venturing, 20: 183-216.

Cohen, W.M. and Levinthal, D.A., 1989. Innovation and Learning: the Two Faces of R\&D, The Economic Journal, 99: 569-596.

Correia, F., Amaral, A. and Magalhães, A., 2002. Public and Private Higher Education in Portugal: unintended effects of deregulation, European Journal of Education, 37: 457-472.

DiGregorio, D., and Shane, S., 2003. Why do some universities generate more start-ups than others?, Research Policy, 32: 209-227.

Faria, P., Lima, F. and Santos, R., 2007. Cooperation in Innovation: Empirical Evidence from an Innovation Survey. Academy of Management, Annual Meeting, Philadelphia, USA.

Feldman, M.P., 2000. Location and innovation: the new economic geography of innovation, In: Clark, G., Feldman, M.P., Gertler, M. (Eds.), Oxford Handbook of Economic Geography. Oxford University Press, Oxford. 
Figueiredo, O., Guimarães, P. and Woodward, D., 2002. Home-field Advantage: Location Decisions of Portuguese Entrepreneurs, Journal of Urban Economies, 52: 341-361.

Fisher, M. M. and Varga, A., 2003. Spatial knowledge spillovers and university research: Evidence from Austria, Annals of Regional Science, 37: 303-322.

Grandi, A. and Grimaldi, R., 2005. Academics' organizational characteristics and the generation of successful business ideas, Journal of Business Venturing, 20: 821-845.

Henderson, R., Jaffe, A.B., Trajtenberg, M., 1998. Universities as a source of commercial technology: a detailed analysis of university patenting, 1965 - 1988, Review of Economics and Statistics, 80: $119-127$.

Horta, H., 2008. On Improving the University Research Base: The Technical University of Lisbon Case in Perspective, Higher Education Policy, 21: 123-146.

Jaffe, A., 1989. Real effects of academic research, American Economic Review, 79: 957 - 969.

Kangasharju, A., 2000. Regional variations in firm formation: Panel and cross-section data evidence from Finland. Papers in Regional Science, 79: 355-373.

Kiker, B.F., and Santos M. C., 1991. Human Capital and Earnings in Portugal, Economics of Education Review, 10(3): 187-203.

Klepper, S., 2002. The capabilities of new firms and the evolution of the US automobile industry, Industrial and Corporate Change, 11: 645-666.

Laursen, K., and Salter, A., 2004. Searching high and low: what types of firms use universities as a source of innovation?, Research Policy, 33: 1201-1215.

Lee, S., Florida, R., and Acs, Z. 2004. Creativity and Entrepreneurship: A Regional Analysis of New Firm Formation, Regional Studies, 38: 879-891.

Lerner, J. 2005. The Universities and the start-up: Lessons from the past two decades, Journal of Technology Transfer, 30: 49-56. 
Lindelof, P. and Lofsten, H., 2004. Proximity as a resource base for competitive advantage: university-industry links for technology transfer, Journal of Technology Transfer, 29(3-4): 311-326.

Markman, G. D., Phan, P.H., Balkin, D.B. and Gianiodis, P.T., 2005. Entrepreneurship and university-based technology transfer, Journal of Business Venturing, 20: 241-263.

Mazzoneli, R. and Nelson, R.R., 2007. Public research institutions and economic catch-up, Research Policy, 36: 1512-1528.

OECD 2002. Science, Technology and Industry - 2002, Paris.

OECD 2007. Main Science and Technology Indicators 2007, Paris.

Rosenbaum, P. and Rubin D., 1983. The Central Role of the Propensity Score in Observational Studies for Causal Effects, Biometrika, 70: 41-55.

Scott, J.T., 2003. Absorptive Capacity and the Efficiency of Research Partnerships, Technology Analysis \& Strategic Management, 15: 247-253.

Sorenson, O. and Audia, G., 2000. The Social Structure of Entrepreneurial Activity: Geographic Concentration of Footwear Production in the U.S., 1940-1989, American Journal of Sociology, 106: 324-362.

Spencer, J.W., 2001. How Relevant if University-based Scientific Research to Private HighTechnology Firms? A United States- Japan Comparison, Academy of Management Journal, 44: $432-440$.

Stahlecker, T. and Koschatzky, K., 2004. On the significance of geographical proximity for the structure and development of newly founded knowledge intensive business service firms, Working Papers Firms and Regions, No. R2/2004, Fraunhofer Institute. 
Stuart, T.E. and Sorenson, O., 2003. The Geography of Opportunity: Spatial Heterogeneity in Founding Rates and the Performance of Biotechnology Firms, Research Policy, 25: 11391157.

Varga, A., 2000. Local Academic Knowledge Transfers and the Concentration of economic activity, Journal of Regional Science, 40: 289-309.

Zucker, L., Darby, M.R. and Armstrong, J., 1998. Intellectual Human Capital and the Birth of U.S. Biotechnology Enterprises, American Economic Review, 88: 290-306.

Zucker, L., Darby, M.R. and Armstrong, J., 2002. Commercializing Knowledge: University Science, Knowledge Capture, and Firm Performance in Biotechnology, Management Science, $48:$ 138-153 
Table 1 - Descriptive statistics

\begin{tabular}{r|cccc}
\hline & Mean & Std. Dev. & Min & Max \\
\hline Pop. Density (inhabitants per km ${ }^{2}$ ) & 252.577 & 809.145 & 6.240 & 7835.059 \\
Workforce Education (No. years) & 6.056 & 0.857 & 1.813 & 9.609 \\
Regional Workforce & 8115.832 & 32343.93 & 52 & 564964 \\
Share of micro firms in the region & & & & \\
(proportion of firms with less than 10 & 85.083 & 5.909 & 46.667 & 100 \\
employees) & & & 0 & 911 \\
Entry (n ${ }^{\text {of new firms) }}$ & 23.534 & 52.746 & 6.5 & 396 \\
Distance to Lisbon (Km) & 198.106 & 99.041 & 3.5 & 463.5 \\
Distance to Oporto (Km) & 174.104 & 116.574 & & \\
\hline
\end{tabular}

Data for 275 regions (municipalities), pooled 1992-2002 
Table 2- Pre-treatment characteristics of regions

\begin{tabular}{r|cccccc}
\hline $\boldsymbol{t}=-\mathbf{2}$ & Pop. Density & No. workers & $\begin{array}{c}\text { Workforce } \\
\text { Education }\end{array}$ & $\begin{array}{c}\text { Share micro } \\
\text { firms }\end{array}$ & $\begin{array}{c}\text { Distance to } \\
\text { Lisbon in Km }\end{array}$ & $\begin{array}{c}\text { Distance to } \\
\text { Oporto in Km }\end{array}$ \\
\hline Treated group & 1132.329 & 6.020 & 80.749 & 178.031 & 167.062 & 1132.329 \\
& $(2447.756)$ & $(0.956)$ & $(5.201)$ & $(110.592)$ & $(104.297)$ & $(2447.756)$ \\
Group A & 117.909 & 4.764 & 82.823 & 197.362 & 179.593 & 117.909 \\
& $(247.854)$ & $(0.816)$ & $(8.128)$ & $(96.985)$ & $(113.731)$ & $(247.854)$ \\
Group B & 863.055 & 5.151 & 78.901 & 177.529 & 119.088 & 863.055 \\
& $(1847.325)$ & $(0.748)$ & $(7.280)$ & $(98.376)$ & $(97.360)$ & $(1847.325)$ \\
\hline
\end{tabular}

Standard errors in brackets

Treated group = municipalities where there was a new higher education institution between 1993 and $1994(t=$ 0)

Group A = municipalities with no. institutions equal to zero

Group B = municipalities with no. institutions constant and different from zero 
Table 3- Propensity scores estimation- probit regression

\begin{tabular}{rc}
\hline in $t=-2$ & Dummy for treatment \\
\hline Distance to Oporto & -0.002 \\
Distance to Lisbon & {$[0.001]$} \\
& -0.001 \\
Regional Workforce $(\log )$ & {$[0.001]$} \\
& $0.544^{* * *}$ \\
Share of micro firms & {$[0.125]$} \\
& $0.071^{* *}$ \\
Constant & {$[0.031]$} \\
& $-11.750 * * *$ \\
Observations & {$[3.279]$} \\
\hline
\end{tabular}

Note: Dummy for treatment equals 1 for treated regions at the time of treatment Standard errors in parentheses

*significant at $10 \%$; ** significant at $5 \%$; *** significant at $1 \%$ 
Table 4- Effect of a new higher education institution on firm entry in regions ATT Estimation with the stratification matching method

\begin{tabular}{rrrrr}
\hline & No. Treated & No. Control & ATT & Std. Err. \\
\hline Difference in the share of new firms between $t=3$ and $t=-2$ & & \\
Control group A+B & 15 & 441 & -2.176 & 1.448 \\
Control group A & 13 & 406 & -2.806 & 2.125 \\
Control group B & 13 & 37 & 0.087 & 2.185 \\
Difference in the share of new firms between $t=5$ and $t=-2$ & & \\
Control group A+B & 15 & 441 & 0.115 & 1.799 \\
Control group A & 13 & 406 & -1.247 & 1.995 \\
Control group B & 13 & 37 & $6.511 *$ & 2.036 \\
Difference in the share of new firms between $t=7$ and $t=-2$ & & \\
Control group A+B & 15 & 441 & -1.489 & 2.146 \\
Control group A & 13 & 406 & -2.712 & 2.593 \\
Control group B & 13 & 37 & 2.436 & 2.319 \\
\hline
\end{tabular}

Note: ATT - Average Treatment effect on the Treated

*significant at $10 \%$; ** significant at $5 \%$; *** significant at $1 \%$

Group $\mathrm{A}=$ municipalities with no. institutions equal to zero

Group B = municipalities with no. institutions constant and different from zero 
Table 5- Effect of a new higher education institution on the entry of knowledge based firms in regions - ATT Estimation with the stratification matching method

\begin{tabular}{ccccc}
\hline & No. Treated & No. Control & ATT & Std. Err. \\
\hline Difference in the share of new firms between $t=3$ and $t=-2$ & & & \\
Control group A+B & 15 & 441 & $23.862^{*}$ & 13.069 \\
Control group A & 13 & 406 & $30.338^{*}$ & 17.132 \\
Control group B & 15 & 35 & 166.945 & 120.570 \\
Difference in the share of new firms between $t=5$ and $t=-2$ & & & \\
Control group A+B & 15 & 441 & $26.739 * *$ & 13.286 \\
$\quad$ Control group A & 13 & 406 & $33.068^{* *}$ & 15.715 \\
$\quad$ Control group B & 15 & 35 & 172.001 & 118.146 \\
Difference in the share of new firms between $t=7$ and $t=-2$ & & & \\
Control group A+B & 15 & 441 & $27.014 *$ & 16.047 \\
$\quad$ Control group A & 13 & 406 & -- & --- \\
Control group B & 13 & 37 & 321.946 & 225.462 \\
\hline
\end{tabular}

Note: ATT - Average Treatment effect on the Treated

*significant at $10 \%$; ** significant at $5 \%$; *** significant at $1 \%$

Group $\mathrm{A}=$ municipalities with no. institutions equal to zero

Group B = municipalities with no. institutions constant and different from zero 
Table 6- Effect of a new higher education institution on the entry of Low-Tech firms in regions - ATT Estimation with the stratification matching method

\begin{tabular}{ccccc}
\hline & No. Treated & No. Control & ATT & Std. Err. \\
\hline $\begin{array}{r}\text { Difference in the share of new firms between } t=3 \text { and } t=-2 \\
\text { Control group A+B }\end{array}$ & 15 & 441 & $-3.989 * * *$ & 1.010 \\
Control group A & 15 & 407 & $-3.484^{* * *}$ & 1.071 \\
Control group B & 15 & 35 & $-4.723^{* * *}$ & 1.461 \\
Difference in the share of new firms between $t=5$ and $t=-2$ & & & \\
Control group A+B & 15 & 441 & $-3.190^{* *}$ & 1.574 \\
Control group A & 15 & 407 & $-3.725 * *$ & 1.599 \\
Control group B & 15 & 35 & 0.792 & 1.620 \\
Difference in the share of new firms between $t=7$ and $t=-2$ & & & \\
Control group A+B & 15 & 441 & $-4.589 * * *$ & 1.914 \\
Control group A & 15 & 407 & $-4.502 * *$ & 2.106 \\
Control group B & 13 & 37 & -2.788 & 2.230 \\
\hline
\end{tabular}

Note: ATT - Average Treatment effect on the Treated

*significant at $10 \%$; ** significant at $5 \%$; *** significant at $1 \%$

Group $\mathrm{A}=$ municipalities with no. institutions equal to zero

Group B = municipalities with no. institutions constant and different from zero 
Table 7- Effect of a new higher education institution on the entry of different knowledge based sectors - ATT Estimation with the stratification matching method

\begin{tabular}{|c|c|c|c|c|}
\hline & No. Treated & No. Control & ATT & Std. Err. \\
\hline \multicolumn{5}{|c|}{ High-Tech firms } \\
\hline \multicolumn{5}{|c|}{ Difference in the share of new firms between $t=3$ and $t=-2$} \\
\hline Control group $\mathrm{A}+\mathrm{B}$ & 15 & 441 & -0.138 & 17.746 \\
\hline Control group A & 15 & 407 & 2.997 & 20.439 \\
\hline Control group B & 15 & 35 & --- & --- \\
\hline \multicolumn{5}{|c|}{ Difference in the share of new firms between $t=5$ and $t=-2$} \\
\hline Control group $\mathrm{A}+\mathrm{B}$ & 15 & 441 & -4.219 & 19.251 \\
\hline Control group A & 15 & 407 & -3.649 & 13.738 \\
\hline Control group B & 15 & 35 & --- & --- \\
\hline \multicolumn{5}{|c|}{ Difference in the share of new firms between $t=7$ and $t=-2$} \\
\hline Control group $\mathrm{A}+\mathrm{B}$ & 15 & 441 & -13.088 & 20.797 \\
\hline Control group A & 15 & 407 & -13.080 & 22.898 \\
\hline Control group B & 15 & 35 & --- & --- \\
\hline \multicolumn{5}{|c|}{ ICT firms } \\
\hline \multicolumn{5}{|c|}{ Difference in the share of new firms between $t=3$ and $t=-2$} \\
\hline Control group $\mathrm{A}+\mathrm{B}$ & 15 & 441 & 2.857 & 13.507 \\
\hline Control group A & 15 & 407 & 5.983 & 13.647 \\
\hline Control group B & 15 & 35 & --- & --- \\
\hline \multicolumn{5}{|c|}{ Difference in the share of new firms between $t=5$ and $t=-2$} \\
\hline Control group $\mathrm{A}+\mathrm{B}$ & 15 & 441 & -3.271 & 9.999 \\
\hline Control group A & 15 & 407 & 0.146 & 11.467 \\
\hline Control group B & 15 & 35 & & \\
\hline \multicolumn{5}{|c|}{ Difference in the share of new firms between $t=7$ and $t=-2$} \\
\hline Control group $\mathrm{A}+\mathrm{B}$ & 15 & 441 & -7.626 & 9.507 \\
\hline Control group A & 15 & 407 & -3.842 & 11.139 \\
\hline Control group B & 13 & 37 & --- & --- \\
\hline \multicolumn{5}{|c|}{ Knowledge intensive service firms } \\
\hline \multicolumn{5}{|c|}{ Difference in the share of new firms between $t=3$ and $t=-2$} \\
\hline Control group $\mathrm{A}+\mathrm{B}$ & 15 & 441 & -0.997 & 2.697 \\
\hline Control group A & 15 & 407 & 1.143 & 3.239 \\
\hline Control group B & 15 & 35 & 3.459 & 6.148 \\
\hline \multicolumn{5}{|c|}{ Difference in the share of new firms between $t=5$ and $t=-2$} \\
\hline Control group $\mathrm{A}+\mathrm{B}$ & 15 & 441 & 2.778 & 2.879 \\
\hline Control group A & 15 & 407 & 5.396 & 3.388 \\
\hline Control group B & 13 & 37 & $9.942 * * *$ & 3.868 \\
\hline \multicolumn{5}{|c|}{ Difference in the share of new firms between $t=7$ and $t=-2$} \\
\hline Control group $\mathrm{A}+\mathrm{B}$ & 15 & 441 & 0.785 & 3.135 \\
\hline Control group A & 15 & 407 & 1.558 & 3.272 \\
\hline Control group B & 13 & 37 & 8.489 & 7.675 \\
\hline
\end{tabular}

Note: ATT - Average Treatment effect on the Treated

*significant at $10 \% ; * *$ significant at $5 \% ; * * *$ significant at $1 \%$

Group $\mathrm{A}=$ municipalities with no. institutions equal to zero

Group B = municipalities with no. institutions constant and different from zero 
Appendix 1 - Sectors considered (OECD, 2002)

High-technology industries:

- Aircraft and spacecraft (35.3)

- Pharmaceuticals (24.4)

- Office and computing machinery (30)

- Radio, TV and communication equipment (32)

- Medical, precision and optical equipment (33)

Medium-High-Technology industries:

- Chemicals excluding pharmaceuticals (24 except 24.4)

- Machinery and equipment (29)

- Electrical machinery and apparatus (34)

- Motor vehicles and trailers (34)

- Railroad and transport equipment $(352+359)$

Medium-Low-Technology industries:

- Coke, refined petroleum products and nuclear fuel (23)

- Rubber and plastic services (25)

- Other non-metallic mineral products (26)

- Basic Metals (27)

- Fabricated metal products except machinery and equipment (28)

- Building and repairing of ships and boats (351)

Low technology industries:

- Food products, beverages and tobacco (15-16)

- Textile, textile products, leather and footwear (17-19)

- Wood, pulp, paper, paper products, printing and publishing (21-22)

- Manufacturing and recycling (21-22)

Information and Communication Technologies industries (ICT):

- Office and computing machinery (30)

- Radio, TV and communication equipment (32)

- Medical, precision and optical equipment (33)

- Post and Communication (64)

- Computer and related activities (72)

Knowledge based industries (KBE):

- High-technology industries: Aircraft and spacecraft (35.3) + pharmaceuticals (24.4) + Office and computing machinery (30) + Radio, TV and communication equipment (32) + Medical, precision and optical equipment (33)

- Medium-High-Technology: Chemicals excluding pharmaceuticals (24 except. 24.4) + Machinery and equipment (29)+ Electrical machinery and apparatus (34)+ motor vehicles and trailers (34) + Railroad and transport equipment $(352+359)$

- $\quad$ Post and Communication (64)

- Finance and insurance (65-67)

- Business services (71-74) 